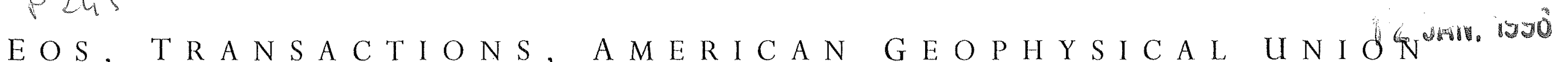
VOLUME 76 NUMBER 39 SEPTEMBER 26, 1995

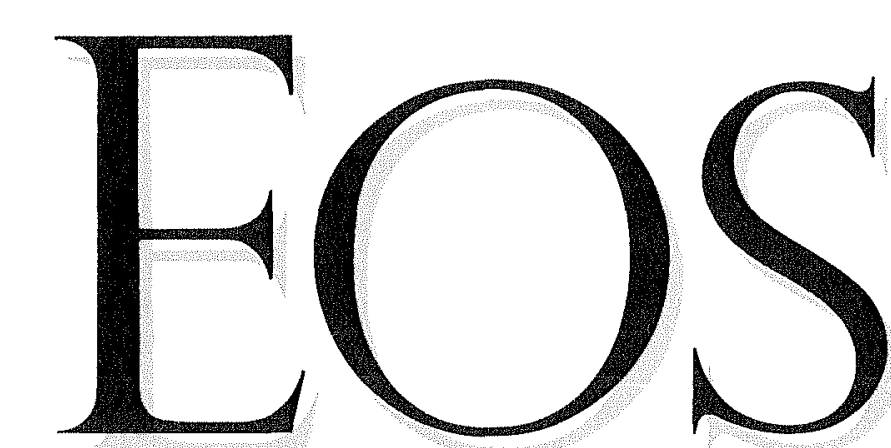

\title{
Satellites Work in Tandem to Improve Accuracy of Data
}

Global observation of the oceans by satellite altimetry entered a new era with U.S./French TOPEX/POSEIDON missions which were launched in July 1991 and August 1992, respectively. For the first time, two altimetric satellites were flying simultan ously. TOPEX/POSEIDON (TP) is an precise observation of the large-scale oceanic circulation. ERS-1 is a multimission satellite. It carries a Synthetic Aperture Rad (SAR), a wind scaterometer, an along-track scann TP radiomeler and a adar allimeter. plementary space-time sampling of the oceanic circulation but they do not obtain data with the same accuracy. The accurate determithan on tion, and specially thr radial component, is a tion of the sea level. The radial component the TP orbit is determined to within $3 \mathrm{~cm}$, white ERS-1 orbits are only determined to are flying simultaneously, the nond are flying sim 1 laneously, the more precise
TP data can be used to correct the ERS-1 orb error [Le Traon et al. 1995a].

To correct the ERS-1 orbit error, a method based on a minimization of crossover differcrossover difere ured sea surface height at a crossover point between two satellite arcs. The difference is mainly due to orbit error if the ocean topog phy ars da chello mich between and ERS-1 arcs (TP-E crossover differences)

and between two ERS-1 arcs (E-E crossover differences) are jointly minimized in the

FRS-1 135 thod was recently applied to the full tRS-1 35-day repeat cycle mission, which lo December 1993 [Le Traon et al. 1995b]. To e consistent with TP orbits, which use the RS-1 JGM-2 orbits are used For all processed ycles, the root mean square (rms) E-E cross over difference before orbit error correctio is $18 \mathrm{~cm}$ for time lags below 5 days. The The orbit error correction provided aver efficient reduction of E-E crossover differences. For time lags of less than 5 days, the ms of corrected E-E crossover differences is ways below 7.5 cm tor each processed cydata. The correction also provides a very effcient reduction of TP-E crossover differences, which are always below $7 \mathrm{~cm}$ rms. The mean $T P-E$ crossover difference before lion of the difference between the ERS-1 and TOPEX instrumental range biases This relalive bias is about $26 \mathrm{~cm}$. Assuming a $15 \mathrm{~cm}$ TOPEX bias, this means that ERS-1 measures too short by about $41 \mathrm{~cm}$. This result is in exThe ags 1 satelite exatly repeats its ground track pattern every cycle (every days). The observed temporal variations of the sea level along the satellite tracks are due

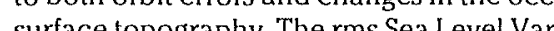
ability (SLY) deduced from uncorrected
IN THIS ISSUE: APPROPRIATIONS FOR SCIENCE MOVE AHEAD IN CONGRESS, PAGE 387 - LAKE DRILLING SITES FOR

CONTINENTAL PALEOCLIMATE RESEARCH SOUGHT, PAGE 388

FOR REFERENCE: WESTERN PACIFIC GEOPHYSICS MEETING CALL FOR PAPERS AND SESSION DESCRIPTIONS, SEPTEMBER 19, 1995

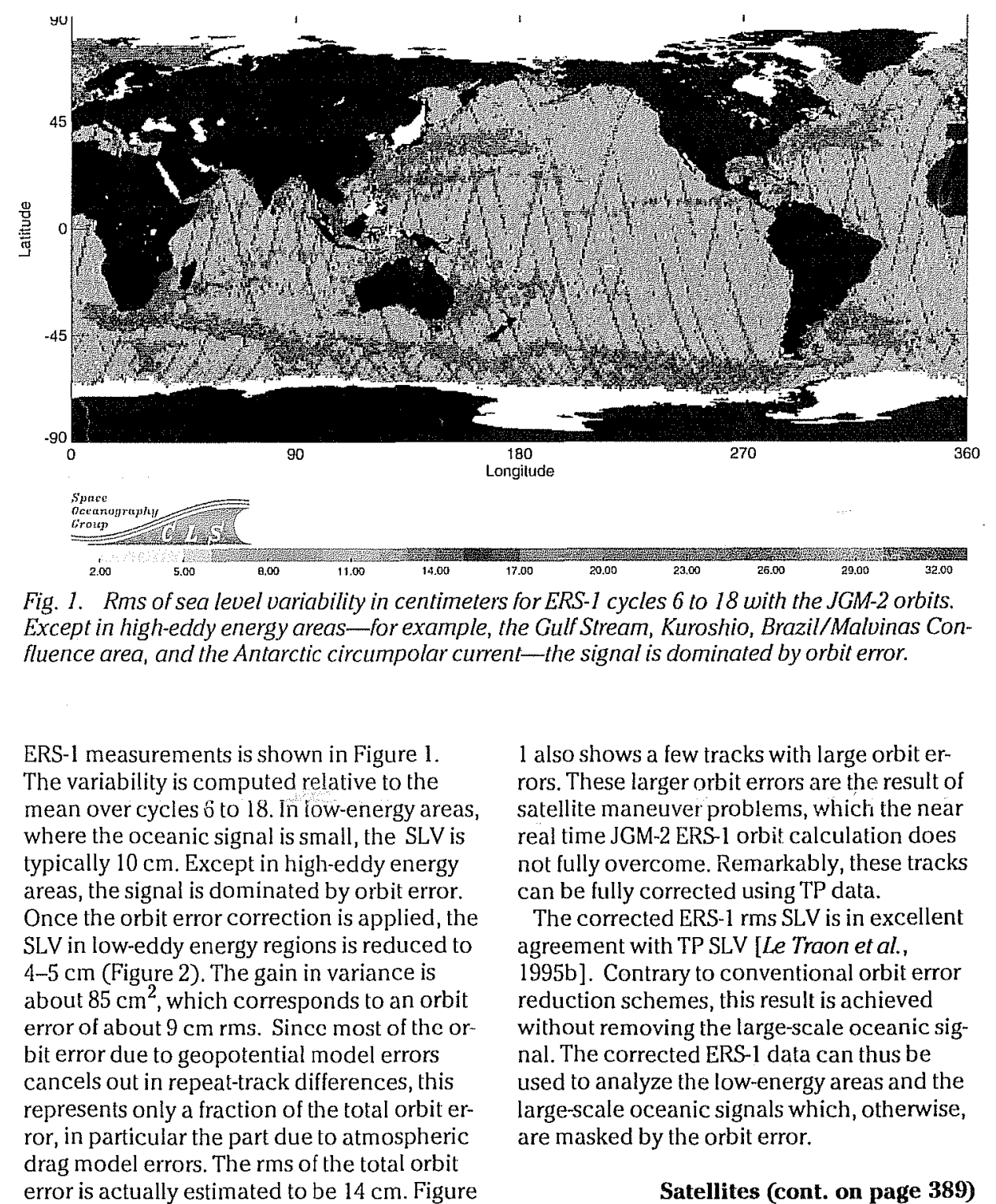




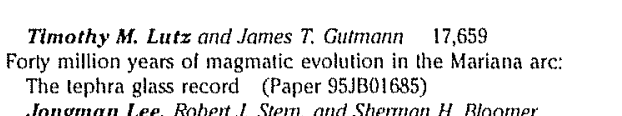

Individual articles or "separates" from AGU
research and review iournals cas

(hased diectly from AGU

"able of Contents appears in the "AGU Publica

ber given at the end of the paper title. The

(\$2.50 for individuals with AGU separale de

posit accounts) and $\$ 1.00$ for each additional
article. Because of the limiled supply of sepa-

can be ordered. Payment must accompany

your order, unless you have a deposit acco

counts, contact AGU headquarters.)

Send your order to: American Geophysica
Union, 2000 Florida Avenue, N. W., Washing-
ton, DC 20009, or call 1-800-966-2481
Ordering Separates

tions" section of Eos. (Separates are not aval-

Journal of Geophysical Research Volume 100 Number B9 September 10, 1995

Papers on
Chentatry
Volcaulogy
Sellogy

Seventy-ffth Anulversary Papper

(75) Mantle plumes and flood basalts (Paper 95.1801589)

Tiul laboratory experiments (Paper 951801460)

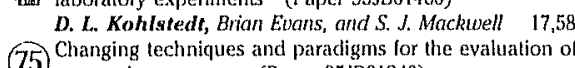

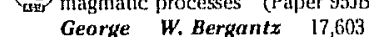

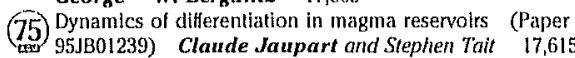
Resulur Papers

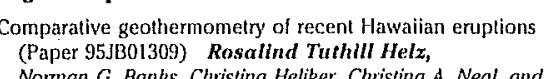

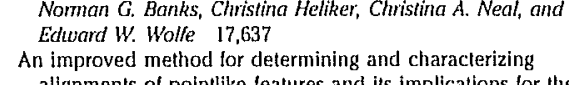

\section{Satellites (cont. from page 385)}

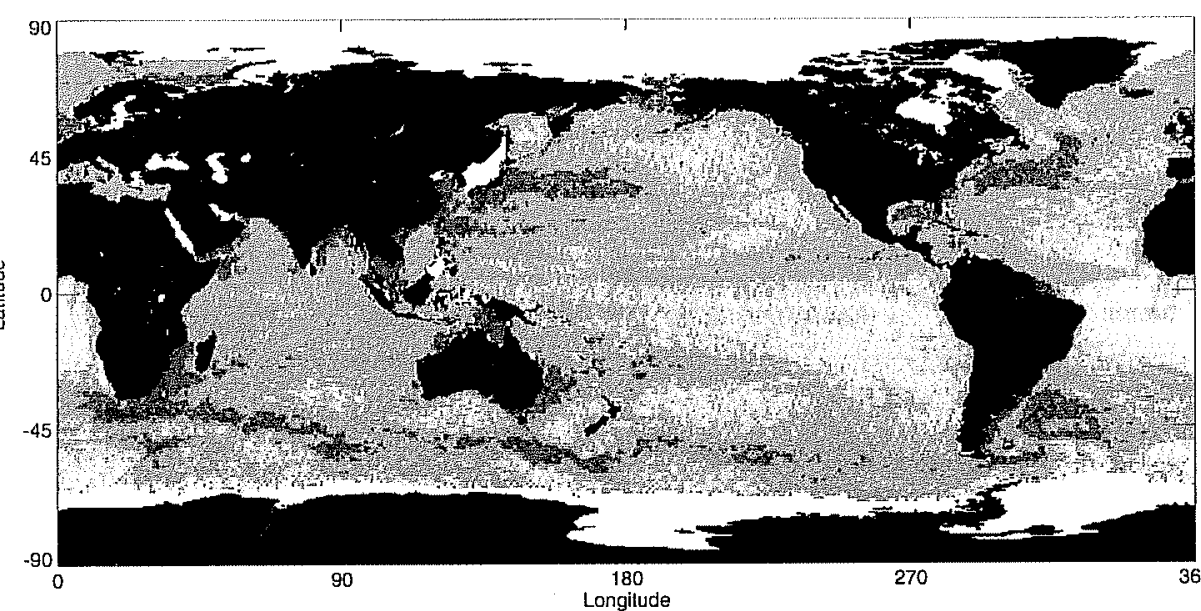

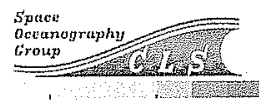
Fig. 2. Rms of sea level variability in centimeters for ERS-1 cycles 6 to 18 after correction w

Corrected Data Sets Available

The corrected ERS-1 data set is distributed on CD-ROM by AVISO, the French TP proce ing and archy cal Data Record, which provides the sea-surface height with all altimetric corre tions applied, and a file of Sea Level
Variability. Similar files for TP are also distribmonitoring of the sea level and oceanic circe lation will require homogeneous times series of sea level from Geosat, TOPEX/POSEIDON and TOPEX Follow-On det This sty is first step toward this very challenging goa Acknowledgments: We thank Remko Sch roo for providing the ERS-1 JGM-2 orbits. The study was funded by CNES/AVISO under conprovided by ESA as part of the proposal Ogor, and J. Dorandeu, CLS Space Oceanog Dhy Group, Toulouse France

References

Le Traon, P. Y., P. Gaspar, F. Bouyssel,
and H. Makhmara, USing TOPEXXPOSELI-
DON data to enhance ERS-1 orbit, $J$. DON data to enhance ERS-1 orbit, $J$. Le Traon, P. Y., P. Gaspar, F. Ogor, an data using TOPEX/POSEIDON data as a reference, technical report, CNES/CLS con-
ent GO/94/522. (available on the AVISO Home Page (asale.fr), 1995b.
http://www-aviso.cls.cnes.r.

\section{Elatera}

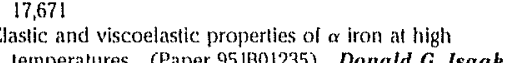

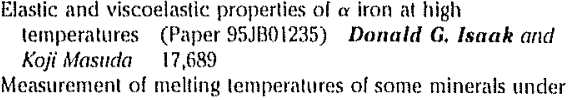

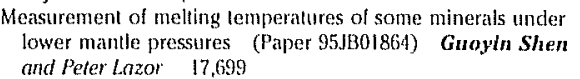

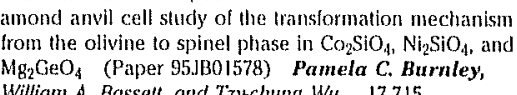

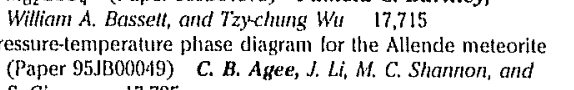

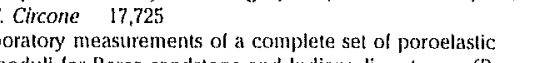

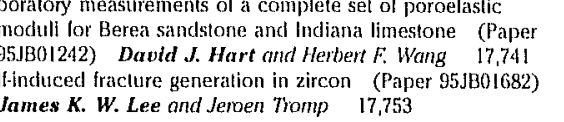
Papers on
Geomagnettsm and Paleomagnetlem
Marrine Geology and Geophystcs

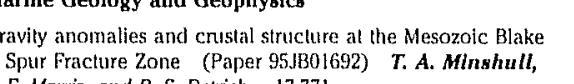

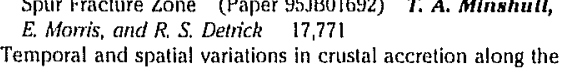

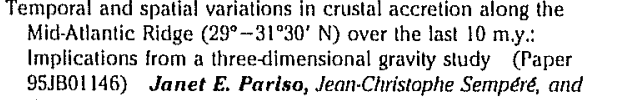

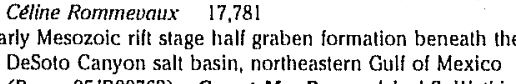
177,955 .

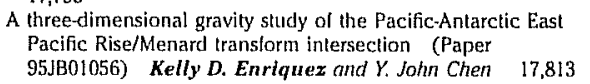

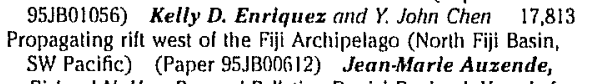

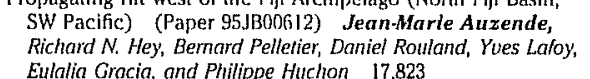

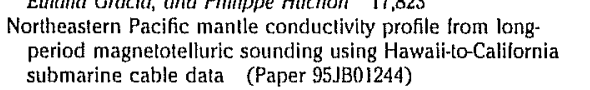

WATER QUALITY MEASURH ACCURACY AND UNMA NOW AVAILABLE IN THE U.S.A LAKE AND BOREHOLE APPLI! SENSORS. INTERNAL RECI
DATA TELEMETRY . NO I - CONDUCTIVITY (50 ms time consti $0.003 \mathrm{mS} / \mathrm{cm}$ accuracy and stabil externally accessible cell allows easy call with 1 anper shed Tell maintenance is performed with cotton
TEMPERATURE (50 ms time const $0.003^{\circ} \mathrm{C}$ accuracy and stability per OXYGEN $3 \mathrm{~s}$ time constant $0.1 \mathrm{ppm}$ accuracy, water pumping not re
pH RECORDING Internal recording: $10 \mathrm{~Hz}$ max. rate; 20 ho 45 days operations on AA cells, dependin ; longer periods and real-time readout, etc. - DIMENSION AND WEIGHT -1500 dbar: 75 dia. $\times 685 \mathrm{~mm}, 1.8 \mathrm{~kg}$.
-7000 dbar: 100 dia. $\times 710 \mathrm{~mm}, 12 \mathrm{~kg}$. (1) IDRONAUT Via Monte Amiata, 10
20047 Brugherio (MILANO) Fax
e-mail
idronaut 398382
(d)

\section{Where, when or however you need UVB check our references.}

